\title{
Association of Integrated Mental Health Services with Physical Health Quality Among VA Primary Care Patients
}

\author{
Lucinda B. Leung, MD, PhD, MPH ${ }^{1,2}$ (D), Lisa V. Rubenstein, MD, MSPH 2,3,4, \\ Erin Jaske, $M P H^{5}$, Leslie Taylor, $P h D^{5}$, Edward P. Post, $M D, P h D^{6,7}$, \\ Karin M. Nelson, MD, MSHS ${ }^{5,8}$, and Ann-Marie Rosland, MD, MS 9,10
}

\begin{abstract}
'Center for the Study of Healthcare Innovation, Implementation, \& Policy, VA Greater Los Angeles Healthcare System, 11301 Wilshire Blvd (1 11 G), Los Angeles, CA, USA; 'Division of General Internal Medicine and Health Services Research, UCLA David Geffen School of Medicine, Los Angeles, CA, USA; ${ }^{3}$ Department of Health Policy \& Management, UCLA Fielding School of Public Health, Los Angeles, CA, USA; ${ }^{4}$ RAND Corporation, Santa Monica, CA, USA; ${ }^{5}$ VA Puget Sound Health Care System, Seattle, WA, USA; ${ }^{6}$ VA Ann Arbor, Center for Clinical Management Research, Ann Arbor, MI, USA; ${ }^{7}$ Department of Medicine, University of Michigan Medical School, Ann Arbor, MI, USA; ${ }^{8}$ Department of Medicine, University of Washington Medical School, Seattle, WA, USA; 'VA Center for Health Equity Research and Promotion, VA Pittsburgh Healthcare System, Pittsburgh, PA, USA;

${ }^{10}$ Department of Internal Medicine, University of Pittsburgh School of Medicine, Pittsburgh, PA, USA.
\end{abstract}

BACKGROUND: Integrated care for comorbid depression and chronic medical disease improved physical and mental health outcomes in randomized controlled trials. The Veterans Health Administration (VA) implemented Primary Care-Mental Health Integration (PC-MHI) across all primary care clinics nationally to increase access to mental/behavioral health treatment, alongside physical health management.

OBJECTIVE: To examine whether widespread, pragmatic PC-MHI implementation was associated with improved care quality for chronic medical diseases.

DESIGN, SETTING, AND PARTICIPANTS: This retrospective cohort study included 828,050 primary care patients with at least one quality metric among 396 VA clinics providing PC-MHI services between October 2013 and September 2016.

MAIN MEASURE(S): For outcome measures, chart abstractors rated whether diabetes and cardiovascular quality metrics were met for patients at each clinic as part of VA's established quality reporting program. The explanatory variable was the proportion of primary care patients seen by integrated mental health specialists in each clinic annually. Multilevel logistic regression models examined associations between clinic PC-MHI proportion and patient-level quality metrics, adjusting for regional, patient, and time-level effects and clinic and patient characteristics.

KEY RESULTS: Median proportion of patients seen in PC-MHI per clinic was 6.4\% (IQR=4.7-8.7\%). Nineteen percent of patients with diabetes had poor glycemic control (hemoglobin Alc >9\%). Five percent had severely elevated blood pressure ( $>160 / 100 \mathrm{mmHg}$ ). Each two-fold increase in clinic PC-MHI proportion was associated with $2 \%$ lower adjusted odds of poor glycemic control $(95 \%$

Prior presentations: This abstract was accepted at Society of General Internal Medicine 2020 Annual Meeting.

Received June 28, 2021

Accepted November 17, 2021

Published online February 9, 2022
$\mathrm{CI}=0.96-0.99 ; p=0.046)$ in diabetes. While there was no association with quality for patients diagnosed with hypertension, patients without diagnosed hypertension had $5 \%(\mathrm{CI}=0.92-0.99 ; p=0.046)$ lower adjusted odds of having elevated blood pressures.

CONCLUSIONS AND RELEVANCE: Primary care clinics where integrated mental health care reached a greater proportion of patients achieved modest albeit statistically significant gains in key chronic care quality metrics, providing optimism about the expected effects of large-scale PC-MHI implementation on physical health.

KEY WORDS: Health services; Mental health; Diabetes; Hypertension; Veterans.

J Gen Intern Med 37(13):3331-7

DOI: $10.1007 / \mathrm{s} 11606-021-07287-2$

This is a U.S. government work and not under copyright protection in the U.S.; foreign copyright protection may apply 2022

\section{INTRODUCTION}

More than half of US adults have two or more chronic diseases, oftentimes a mix of physical and mental health conditions (comorbidity). ${ }^{1}$ For example, more than half of patients with depression have been documented having concurrent medical disease. ${ }^{2}$ Having both physical and mental health comorbidities is associated with significant negative impacts on condition management and health. Mental health comorbidities have been associated with approximately 10 to 20 years of premature mortality, mostly due to inadequately controlled physical health problems. ${ }^{3}$ Comorbidity is also costly to health systems. Medicare patients with comorbidity have $65 \%$ higher costs compared to those without comorbidity. ${ }^{4}$ Veterans who are at high risk for hospitalization in VA have also been found to heavily use both mental health and primary care services. ${ }^{5}$ As a result, many health systems strive to provide integrated mental health care modeled after 
evidence-based collaborative care which embeds mental health case managers and consulting psychiatrists in primary care settings. ${ }^{6}$

Growing evidence suggests that integrated mental health care can lead to better control of chronic physical health conditions, such as diabetes and cardiovascular disease. ${ }^{7,8}$ Few studies have been able to quantify the effects of integrated mental health care on physical health outcomes in pragmatic settings. ${ }^{9}$ Among fourteen clinics in one health system $(n=218$ patients), a randomized controlled trial (RCT) of collaborative care management for depression and diabetes reported significant reductions in hemoglobin $\mathrm{A} 1 \mathrm{c}$ (HbA1c) (as compared to controls, $0.58 \%$ difference, over 12 months), and improvements in depression symptoms, cholesterol, blood pressure, and quality of life. ${ }^{10}$ Subsequently, the COMPASS trial replicated these findings when diabetes-depression collaborative care was implemented among 172 clinics in eight states ( $n=3609$ patients). ${ }^{11}$ Despite evidence that integrated mental health care can be effective for managing comorbid chronic physical conditions, it is unclear whether positive patient outcomes extend to pragmatically (and variably) implemented integrated care models, i.e., outside of small patient populations and controlled clinical trial settings. ${ }^{12}$

Since 2008, the Veterans Health Administration (VA) has integrated mental health services into all primary care practices nationwide through its Primary Care-Mental Health Integration (PC-MHI) program, which is based on established collaborative care models. ${ }^{13}$ In 2010 , the VA began implementing a multidisciplinary patient-centered medical home model called Patient Aligned Care Teams (PACT) ${ }^{14}$ While care model implementation can vary from site-to-site, ${ }^{15} \mathrm{PC}$ MHI generally increased behavioral health staff and resources to support primary care teams in treating mental health conditions and addressing health behaviors including sleep, stress, and self-management of chronic physical health conditions. PC-MHI implementation has been found to increase patient use of outpatient primary and mental health care, and reduce non-mental health specialty care use, hospitalizations, and total costs of care among VA primary care patients. ${ }^{16}$ It is unknown whether these changes in utilization were related to PC-MHI-associated improvements in chronic physical health management. While one of the original goals of PC-MHI implementation was to improve mental health care access, it is possible that greater care integration led to positive indirect effects on the physical health of primary care patients. The widespread, successful implementation of PC-MHI across VA nationally offers an opportunity to examine effects of integrated mental health care on multiple chronic disease process and patient outcomes, to our knowledge, for the first time.

In this study, we examined, over 3 years, how the proportion of clinic patients seen by integrated mental health specialists was associated with patients' diabetes and hypertension quality metrics in all VA primary care clinics mandated to have on-site PC-MHI programs full-time (i.e., serving 5,000+ patients). We hypothesized that patients assigned to primary care clinics with higher use of integrated mental health care would have higher odds of meeting chronic physical health condition control metrics (e.g., glycemic and blood pressure control), and secondarily, process metrics (e.g., diabetic retinopathy screening).

\section{METHODS}

\section{Study Design and Cohort}

This is a retrospective repeated cross-sectional study of 828,050 primary care patients whose health records were randomly sampled by VA's quality monitoring program on October 1, 2013, to September 30, 2016. The VA External Peer Review Program ${ }^{17}$ reviews an independent probability sample of patient electronic health records across all VA clinics nationally. All patients sampled had a VA visit during the previous 13-24 months, and a VA primary care visit during the 12 months prior to and during the month preceding sampling. Patients were assigned to one of 396 VA primary care clinics (153 hospital-based, 243 community-based) mandated to offer on-site integrated mental health services. Cohorts were assembled for each of the following disease conditions: diabetes $(n=135,819)$, hypertension $(n=249,121)$, no diagnosed hypertension $(n=166,000)$, cardiovascular disease $(n=63,627)$.

\section{Measures}

The explanatory variable (clinic-level) approximated the reach of integrated PC-MHI services within each primary care clinic. ${ }^{16}$ It was calculated as the proportion of assigned primary care patients who saw a PC-MHI specialist in each clinic per study year. Clinic PC-MHI proportion is an existing performance metric obtained from the VA Support Service Center (VSSC). Because PC-MHI programs were simultaneously implemented across all VA clinics nationwide, it is challenging to identify non-PC-MHI clinics as comparators for evaluation. PC-MHI proportion, which varies by clinic over time, has therefore been used in research studies to estimate the level of mental health integration within primary care clinics during each year of outcome measurement. ${ }^{13,18,19}$ For regression models, we performed log base 2 transformation to normalize data distribution of this variable.

Primary outcomes (patient-level) were measures of diabetes and hypertension control over 12 months, mostly analogous to Healthcare Effectiveness Data and Information Set (HEDIS) measures. For each patient, appropriate glycemic control was defined as HbAlc $\leq 9$, versus $>9$ (or not done). Two metrics for appropriate hypertension control rated whether patients' last blood pressure was $<140 / 90$, versus $<160 / 100 \mathrm{mmHg}$ (or not done). Secondary process outcomes related to chronic disease care included (1) whether patients with diabetes and/ or cardiovascular disease had low-density lipoprotein (LDL) cholesterol $<100 \mathrm{mg} / \mathrm{dL}$ or were taking moderate-intensity 
statin medications (data only available from fiscal years 2014 2015), and (2) whether patients with diabetes obtained timely retinal screening exams, annually (if retinopathy) or every 2 years (if no retinopathy).

Study covariates included clinic and patient-level variables chosen a priori from hypothesized associations with both care quality and mental health use in primary care. Patient age, gender, race-ethnicity, marital status, VA means test (which determines level of copayment charged for VA services), service-connected disability (which helps determine eligibility and payment for specific VA services), and distance from patient home to assigned primary care site were obtained from VA administrative data. We included each clinic's PACT Implementation Progress Index $\left(\mathrm{PI}^{2}\right)$, which measures degree of implementation of core PACT components (e.g., access, care coordination). ${ }^{20} \mathrm{PI}^{2}$ has been found to be associated with chronic condition care quality, ${ }^{21}$ but not PC-MHI proportion. ${ }^{16} \mathrm{We}$ also included clinic type (hospital- versus community-based) and location (rural versus nonrural). Clinic size was represented by the number of primary care patients assigned to that site at the end of each year.

We included patient mental health diagnoses (i.e., depression, anxiety, posttraumatic stress disorder, alcohol and substance use disorders [SUD], schizophrenia, bipolar disorder), defined by at least two occurrences of International Classification of Diseases (ICD)-9 and -10 diagnostic codes found in outpatient (at least one for SUD only) or one in inpatient encounter claims for each FY. We also indicated homeless status for any occurrence of ICD coding. We included Gagne et al.'s comorbidity score, ${ }^{22}$ which is based on conditions included in the Charlson Index and the Elixhauser comorbidity system. The score was subdivided into three levels of severity for each patient in each year, based on the VA primary care population distribution.

\section{Analyses}

We described patient and clinic characteristics and mean proportion of patients meeting each quality outcome measure. In separate multilevel logistic regression models for each outcome quality metric, we examined how clinic PC-MHI proportion predicted patient odds of meeting the quality metric, controlling for year, VA region, clinic, and patient characteristics. Time (year) and regional fixed effects were included to account for secular trends and time-invariant regional effects. We also included patient random effects, because of presence of multiple non-independent observations per patient over 3 years. We accounted for multiple testing for all outcomes using the Benjamini-Hochberg Procedure. ${ }^{23}$

In sensitivity analyses, we restricted models to only patients with comorbid physical and mental health diagnoses, hypothesizing there would be greater impact on physical care quality among patients with diagnosed mental health needs. For all models, we determined significance using a two-tailed $\alpha$ of 0.05 and analyzed data in SAS version 9.4 and Stata version 14.

This study was conducted as part of an ongoing VA Office of Primary Care quality improvement effort to understand PCMHI's impact on care access and quality. ${ }^{13,18,19}$ It was designated as exempt from Institutional Review Board review.

Table 1 Characteristics of Study Cohort Across 396 VA Primary Care Clinics, 2013-2016

\begin{tabular}{|c|c|}
\hline & $\begin{array}{l}\text { Number }(\%)(n=828,050 \\
\text { unique patients) }\end{array}$ \\
\hline Age mean (SD) (years) & $63.66(15.2)$ \\
\hline Female & $112,416(13.6)$ \\
\hline \multicolumn{2}{|l|}{ Race/Ethnicity } \\
\hline White, non-Hispanic & $595,020(71.9)$ \\
\hline Black, non-Hispanic & $144,354(17.4)$ \\
\hline Hispanic & $53,304(6.4)$ \\
\hline Other & $35,372(4.3)$ \\
\hline \multicolumn{2}{|l|}{ Marital status } \\
\hline Single & $106,056(12.8)$ \\
\hline Married & $399,446(48.2)$ \\
\hline Divorced/Separated/Widowed & $322,547(39)$ \\
\hline \multicolumn{2}{|l|}{ VA means test status } \\
\hline Exempt & $156,253(18.9)$ \\
\hline Any copay required & $118,877(14.4)$ \\
\hline Testing not required, or missing & $552,920(66.8)$ \\
\hline \multicolumn{2}{|l|}{ Service-connected disability rating } \\
\hline $0 \%$ & $233,844(33.5)$ \\
\hline $1-50 \%$ & $158,659(22.7)$ \\
\hline $51-100 \%$ & $306,174(43.8)$ \\
\hline $\begin{array}{l}\text { Homelessness documented in medical } \\
\text { record }\end{array}$ & $53,345(6.4)$ \\
\hline \multicolumn{2}{|l|}{ Gagne comorbidity score } \\
\hline Low (bottom 25\%) & $123,554(14.9)$ \\
\hline Intermediate (middle $25-75 \%$ ) & $498,643(60.2)$ \\
\hline High (top 25\%) & $205,853(24.9)$ \\
\hline \multicolumn{2}{|l|}{ Mental health diagnoses } \\
\hline Depression & $266,771(32.2)$ \\
\hline Posttraumatic stress disorder & $182,486(22.0)$ \\
\hline Substance use disorder & $160,604(19.4)$ \\
\hline Anxiety disorder & $145,963(17.6)$ \\
\hline $\begin{array}{l}\text { Serious mental illness (e.g., } \\
\text { schizophrenia, bipolar) }\end{array}$ & $71,144(8.6)$ \\
\hline $\begin{array}{l}\text { Average distance traveled to clinic } \\
\text { (miles) }\end{array}$ & $16.03(16.8)$ \\
\hline \multirow{2}{*}{\multicolumn{2}{|c|}{$\begin{array}{l}\text { Primary chronic disease quality outcomes - physiologic control metrics } \\
\text { Diabetes related }\end{array}$}} \\
\hline & \\
\hline $\begin{array}{l}\text { Hemoglobin A1c }>9 \text { or not done } \\
(n=135,819)\end{array}$ & $26,599(19.6)$ \\
\hline Blood pressure $>140 / 90$, among & $28,920(21.3)$ \\
\hline $\begin{array}{l}\text { Blood pressure } \geq 160 / 100, \text { or not done } \\
(n=135,819)\end{array}$ & $8,152(5.3)$ \\
\hline Hypertension (HTN) related & \\
\hline Diagnosed HTN, blood pressure $\geq 160 /$ & $15,152(6.1)$ \\
\hline 100, or not done $(n=249,121)$ & \\
\hline $\begin{array}{l}\text { No HTN diagnosis, blood pressure } \\
>140 / 90(n=166,000)\end{array}$ & $16,515(9.9)$ \\
\hline No HTN diagnosis, blood pressure $\geq$ & $5,069(3.1)$ \\
\hline $160 / 100$, or not done $(n=166,000)$ & \\
\hline \multicolumn{2}{|c|}{ Secondary chronic disease quality outcomes - process metrics } \\
\hline $\begin{array}{l}\text { No timely diabetes retinal exam } \\
(n=135,735)\end{array}$ & $14,000(10.3)$ \\
\hline $\begin{array}{l}\text { LDL cholesterol }>100 \text { or no statin } \\
\text { prescribed, among patients with diabetes } \\
(n=96,334)\end{array}$ & $12,942(13.4)$ \\
\hline $\begin{array}{l}\text { LDL cholesterol }>100 \text { or no statin } \\
\text { prescribed, among patients with } \\
\text { cardiovascular disease }(n=63,627)\end{array}$ & $7,316(11.5)$ \\
\hline
\end{tabular}




\section{RESULTS}

Among 828,050 unique VA primary care patients from 396 clinics with available quality monitoring data in FY2014 to FY2016 ( $n=1,130,371$ person-years), 715,634 (86.4\%) were men, 595,020 (71.9\%) white, with a mean (standard deviation [SD]) baseline age of 63.7 (15.2) years (Table 1). Physical and mental health condition rates were high-205,853 (24.8\%) had Gagne comorbidity scores classified in the highest category and 266,771 (32.2\%) had a mental health diagnosis.

Median clinic PC-MHI proportion (or percent of primary care patients seen by integrated mental health specialists) over the study period was $6.3 \%$ (range $=0-36.4 \%$ ). Clinics, on average, served 14,278 ( $\mathrm{SD}=10,421)$ overall patients annually. Most clinics $(75.4 \%)$ were in urban areas and were hospital-based (57.4\%).

A total of $26,599(19.6 \%)$ patients with diabetes had poor glycemic control (HbAlc $>9 \%$ or not done) and 8,152 $(5.3 \%)$ had severely elevated blood pressure $(\geq 160 / 100 \mathrm{mmHg}$ or not done). Among patients diagnosed with hypertension, 15,152 (6.1\%) had severely elevated blood pressure. Among patients without diagnosed hypertension, 149,485 (90.1\%) had blood pressure $<140 / 90 \mathrm{mmHg}$ and 5,069 (3.1\%) had severely elevated blood pressure $>160 / 100 \mathrm{mmHg}$ or not done. A total of $121,734(89.7 \%)$ patients with diabetes received timely retinal exams. Most patients with diabetes (83,392 [86.6\%]) or cardiovascular disease $(56,311$ [88.5\%]) had LDL cholesterol $<100 \mathrm{mg} / \mathrm{dL}$ or were prescribed moderate-dosed statins (Table 1).

In multivariate regression models, clinic PC-MHI proportion was significantly associated with glycemic control among patients with diabetes. Each two-fold increase in proportion of clinic patients seen by PC-MHI specialists was associated with lower odds of poor glycemic control (adjusted odds ratio $[\mathrm{aOR}]=0.98 ; 95 \%$ confidence interval $[\mathrm{CI}]=.96-.99)$ among the clinic's patient population. However, clinic PC-MHI proportion was also associated with higher odds of not receiving timely retinal exams $(\mathrm{aOR}=1.04 ; \mathrm{CI}=1.02-1.07)$ and not having LDL cholesterol $<100 \mathrm{mg} / \mathrm{dL}$ or moderate-dosed statin prescription (aOR=1.03; $\mathrm{CI}=1.003-1.05)$ (Table 2). Appendix Fig. 1 shows the predicted percent of patients meeting quality metrics in clinics of varying PC-MHI proportions, holding all other covariates at the mean.

While there was no observed association between clinic PC-MHI proportion and blood pressure control among veterans with diagnosed hypertension, we found lower odds of severely elevated blood pressure ( $\mathrm{aOR}=0.95 ; \mathrm{CI}=.92-.99)$ per two-fold increase in clinic $\mathrm{PC}-\mathrm{MHI}$ proportion among patients without diagnosed hypertension. However, clinic PC-MHI proportion was also associated with higher odds of not having LDL cholesterol $<100 \mathrm{mg} / \mathrm{dL}$ or moderate-dosed statin prescription $(\mathrm{aOR}=1.04 ; \mathrm{CI}=1.01-1.07)$, among veterans with cardiovascular disease (Table 2).
Table 2 Adjusted Odds of Meeting Chronic Disease Quality Metrics for Each Two-Fold Increase in the Proportion of Primary Care Clinic Patients Seen by PC-MHI Specialist

\begin{tabular}{|c|c|}
\hline & $\begin{array}{l}\text { Adjusted odds ratic } \\
\text { (95\% confidence } \\
\text { interval) }\end{array}$ \\
\hline \multicolumn{2}{|c|}{$\begin{array}{l}\text { Primary chronic disease quality outcomes - physiologic control metrics } \\
\text { Diabetes related }\end{array}$} \\
\hline Hemoglobin A1c $>9$ or not done $(n=135,819)$ & $0.98(0.96-0.99)^{*}$ \\
\hline Blood pressure $>140 / 90$, among patients with & $0.99(0.97-1.00)$ \\
\hline diabetes $(n=135,819)$ & \\
\hline $\begin{array}{l}\text { Blood pressure } \geq 160 / 100, \text { or not done } \\
(n=135,819)\end{array}$ & $0.97(0.94-1)$ \\
\hline Hypertension related & \\
\hline $\begin{array}{l}\text { Diagnosed HTN, blood pressure } \geq 160 / 100 \text {, } \\
\text { or not done }(n=249,121)\end{array}$ & $0.99(0.97-1.01)$ \\
\hline $\begin{array}{l}\text { No HTN diagnosis, blood pressure }>140 / 90 \\
(n=166,000)\end{array}$ & $0.98(0.96-1.00)$ \\
\hline $\begin{array}{l}\text { No HTN diagnosis, blood pressure } \geq 160 / \\
100 \text {, or not done }(n=166,000)\end{array}$ & $0.95(0.92-0.99)^{*}$ \\
\hline \multicolumn{2}{|c|}{$\begin{array}{l}\text { 100, or not done }(n=166,000) \\
\text { Secondary chronic disease quality outcomes - process metrics }\end{array}$} \\
\hline No timely diabetes retinal exam $(n=135,735)$ & $1.04(1.01-1.07)^{*}$ \\
\hline $\begin{array}{l}\text { LDL cholesterol }>100 \text { or no statin prescribed, } \\
\text { among patients with diabetes }(n=96,334)\end{array}$ & $1.03(1.01-1.06)^{*}$ \\
\hline $\begin{array}{l}\text { LDL cholesterol }>100 \text { or no statin prescribed, } \\
\text { among patients with cardiovascular disease } \\
(n=63,627)\end{array}$ & $1.04(1.01-1.08)^{*}$ \\
\hline
\end{tabular}

LDL, low-density lipoprotein. Odds ratios (and 95\% confidence intervals) are derived from multilevel logistic regressions that controlled for clinic Primary Care-Mental Health Integration (PC-MHI) proportion, time (FY), region, patient characteristics (age, sex, racelethnicity, marital status, service-connected disability, VA means testing, Gagne comorbidity score, homelessness status, distance between patients' home addresses and their home clinics, and mental health diagnoses), and clinic characteristics (size, rurality, hospital-versus community-based, patient-centered medical home or Patient Aligned Care Teams implementation progress). ${ }^{*} p<.05$ after accounting for multiple testing using the Benjamini-Hochberg Procedure

Sensitivity analyses conducted by restricting cohort to primary care patients with mental health diagnoses yielded similar results for glycemic control among diabetes patients (Table 2, Appendix Table 3). In diabetes patients, each twofold increase in proportion of clinic patients seen by PC-MHI specialists was associated with, on average, $4 \%$ lower odds of poor glycemic control ( $\mathrm{CI}=.94-.99)$. No significant relationship was observed for other outcomes in this cohort.

\section{DISCUSSION}

In this national study of 828,050 patients from nearly 400 primary care clinics that integrated mental health care, patients at clinics with higher proportions of patients seen by PC-MHI specialists had better glycemic and blood pressure control than those at clinics with lower proportions of patients seen by PCMHI. Few studies have examined outcomes from real-world integrated mental health care programs in large health systems, wherein fidelity to collaborative care models as originally studied is often variable. ${ }^{12,24,25}$ This is the first study we are aware of that examines effects on physical health outcomes when integrated mental health care is widely and pragmatically implemented in a large health system, and that examines 
PC-MHI care across the full primary care population rather than among patients with specific physical health conditions. While effect sizes may seem modest, the population of patients with these chronic conditions is large, so even a small increase in integrated mental health use could lead to clinically significant increases in glycemic and blood pressure control.

Our findings show a significant relationship between the reach of a clinic's primary care mental health integration program and physical health quality performance markers. Clinical trials studying collaborative care for patients with depression plus a specific physical health condition have consistently shown improvements in mental health outcomes (e.g., depression symptoms, mental health-related quality of life) but less consistently shown an impact on the concomitant physical health condition. ${ }^{7}$ Among these trials, collaborative care for depression and diabetes has been studied the most, and has the most documentation of impact on physical health outcomes (i.e., glycemic control). ${ }^{10}$ These studies, however, are RCTs engaging limited patient populations. ${ }^{7,8}$ This level of impact may not be achieved in the real-world setting, where significant variation in methods and quality of providing collaborative care ${ }^{11}$ and patient-centered medical home care in general varies widely. ${ }^{20,26}$ This study provides evidence that collaborative care at the full enrolled patient population level, as implemented across a variety of clinics and settings, can have positive impacts on physical health outcomes for two common physical health conditions.

While integrated mental health care does not typically directly address care of physical health conditions, there are multiple reasons it may have positive effects on diabetes and hypertension control. First, reduced mental health symptoms may make it easier for patients to manage their physical health. ${ }^{27}$ Additionally, better access to mental health care may help primary care clinicians to focus more effectively on managing physical illness. ${ }^{28}$ It is also possible that clinics with high use of integrated mental health care have underlying infrastructure or approaches that facilitate both PC-MHI and higher care quality for physical conditions. ${ }^{29}$ Our findings, however, showed slightly worse overall performance for diabetes exams and statin prescriptions as a clinic's PC-MHI proportion increased, suggesting that the higher PC-MHI clinics may not have provided overall higher quality processes of care. The lack of PC-MHI-associated improvement in chronic disease care processes in the face of improvements in diabetes and hypertension control outcomes may suggest PC-MHI-associated improvements in patient self-management, a pathway that should be investigated in future research.

Research consistently demonstrates patients struggling with mental health conditions have worse physical health. ${ }^{30-32}$ VA patients with mental health diagnoses, however, have been shown to receive equivalent quality of care. ${ }^{33}$ Use of integrated mental health care in this study was also not associated with differences in quality improvements for diabetes and hypertension among patients with known mental health diagnoses than patients without. These findings suggest that patients with or without pre-existing mental health diagnoses benefit equally from PC-MHI, perhaps indicating that integrated care has broader effects on clinic performance than might be expected for an intervention directed at mental health alone. While VA's PC-MHI care model was founded on evidence-based collaborative care to treat mental health conditions, as implemented in clinics, it has evolved to include additional activities for which little evidence on patient outcomes exists. ${ }^{34,35}$ Future research should investigate how PCMHI might impact on physical condition care, including both through better recognition and management of patient distress and, possibly, improved patient-centered management of physical conditions by primary care providers and staff.

Our study has several limitations. First, the study examined an organizational-level explanatory variable, and not the direct effect of PC-MHI service exposure on individuals. While we were not able to include some pertinent organizational characteristics (i.e., primary care and/or mental health care staffing), we were able to control for others (e.g., rural location, clinic size) in our analyses. Second, our outcome data were derived by abstracting a sample of each clinic's patient charts, albeit through an established representative method of monitoring VA care quality. ${ }^{17}$ Future research could compare results to newly available electronic quality measures collected for all VA patients. ${ }^{36}$ Third, our VA administrative data-based diagnosis information may be subject to coding differences because of the transition from ICD9 to ICD-10 diagnostic codes, during which lower coding of certain mental health conditions (such as alcohol use disorders) has been documented. ${ }^{37}$ There is also likely variation in quality of similarly coded mental health services across providers. Finally, this study cannot account for how local versions of PC-MHI differed from each other, and thus cannot link specific program features (e.g., providing direct care for health behavior changes for chronic medical diseases) to results.

In summary, we found that, across a large health system with nationally implemented PC-MHI, patients cared for in primary care clinics where integrated mental health specialists reached a greater proportion of patients had significantly better diabetes and blood pressure control, than those in clinics with lower PC-MHI reach. Experiences of the VA-one of the largest programs to integrate mental health and primary care services to date - provide optimism about the expected effects of large-scale PC-MHI implementation on physical health outcomes. Future evaluations of health care system-wide implementation of integrated mental health care can further investigate the relationships between integrated primary and mental health care and patient physical health outcomes, 
including what specific clinic-level features of PC-MHI have the most impact.

Supplementary Information The online version contains supplementary material available at https://doi.org/10.1007/s11606-02107287-2

Acknowledgements: The authors would like to acknowledge Jessica Severin for her assistance in manuscript preparation.

Corresponding Author: Lucinda B. Leung, $M D, P h D, M P H$; Center for the Study of Healthcare Innovation, Implementation, \& Policy, VA Greater Los Angeles Healthcare System, 11301 Wilshire Blvd (111G), Los Angeles, CA 90073, USA (e-mail: lleung@mednet.ucla.edu).

Funding Dr. Leung is supported by Career Development Award IK2 HX002867 from the United States Department of Veterans Affairs Health Services Research \& Development Service. The views expressed in this article are those of the authors and do not necessarily reflect the position or policy of the US Department of Veterans Affairs or the US government. This work was undertaken as part of the Veterans Administration's Primary Care Analytics Team (Seattle, Washington), supporting and evaluating the VA's transition to a patient-centered medical home. Funding for the Primary Care Analytics Team is provided by the VA Office of Primary Care (Washington, DC).

Open Access This article is licensed under a Creative Commons Attribution 4.0 International License, which permits use, sharing, adaptation, distribution and reproduction in any medium or format, as long as you give appropriate credit to the original author(s) and the source, provide a link to the Creative Commons licence, and indicate if changes were made. The images or other third party material in this article are included in the article's Creative Commons licence, unless indicated otherwise in a credit line to the material. If material is not included in the article's Creative Commons licence and your intended use is not permitted by statutory regulation or exceeds the permitted use, you will need to obtain permission directly from the copyright holder. To view a copy of this licence, visit http://creativecommons. org/licenses/by/4.0/.

\section{REFERENCES}

1. King DE, Xiang J, Pilkerton CS. Multimorbidity trends in united states adults, 1988-2014. J Am Board Fam Med 2018;31(4):503-513. https:// doi.org/10.3122/jabfm.2018.04.180008

2. Yates WR, Mitchell J, Rush AJ, et al. Clinical features of depressed outpatients with and without co-occurring general medical conditions in STAR*D. Gen Hosp Psychiatry 2004;26(6):421-9. https://doi.org/10. 1016/j.genhosppsych.2004.06.008

3. Walker ER, McGee RE, Druss BG. Mortality in mental disorders and global disease burden implications: A systematic review and metaanalysis. JAMA Psychiatry 2015;72(4):334-341.

4. Unutzer J, Schoenbaum M, Katon WJ, et al. Healthcare costs associated with depression in medically ill fee-for-service medicare participants. $J$ Am Geriatr Soc 2009;57(3):506-10. https://doi.org/10.1111/j.15325415.2008.02134.x

5. Chang ET, Zulman DM, Nelson KM, et al. Use of general primary care, specialized primary care, and other veterans affairs services among highrisk veterans. JAMA Netw Open. 2020;3(6):e208120. https://doi.org/10. 1001/jamanetworkopen.2020.8120

6. Tinetti ME, Fried TR, Boyd CM. Designing health care for the most common chronic condition-multimorbidity. JAMA. 2012;307(23):24932494. https://doi.org/10.1001/jama.2012.5265

7. Watson LC, Amick HR, Gaynes BN, et al. Practice-based interventions addressing concomitant depression and chronic medical conditions in the primary care setting: a systematic review and meta-analysis. $J$ Prim Care Community Health 2013;4(4):294-306. https://doi.org/10.1177/ 2150131913484040
8. Atlantis E, Fahey P, Foster J. Collaborative care for comorbid depression and diabetes: a systematic review and meta-analysis. BMJOpen. 2014;4(4)

9. Bodenheimer T, Sinsky C. From triple to quadruple aim: care of the patient requires care of the provider. Ann Fam Med 2014;12(6):573-6. https://doi.org/10.1370/afm.1713

10. Katon WJ, Lin EH, Von Korff M, et al. Collaborative care for patients with depression and chronic illnesses. $N$ Engl $J$ Med. 2010;363(27):26112620. https://doi.org/10.1056/NEJMoa1003955

11. Rossom RC, Solberg LI, Magnan S, et al. Impact of a national collaborative care initiative for patients with depression and diabetes or cardiovascular disease. Gen Hosp Psychiatry. 2017;44:77-85. https:// doi.org/10.1016/j.genhosppsych.2016.05.006

12. Katzelnick DJ, Williams MD. Large-scale dissemination of collaborative care and implications for psychiatry. Psychiatr Serv 2015;66(9):904-6. https://doi.org/10.1176/appi.ps.201400529

13. Post EP, Metzger M, Dumas P, Lehmann L. Integrating mental health into primary care within the veterans health administration. Fam Syst Health 2010;28(2):83-90. https://doi.org/10.1037/a0020130

14. Rosland AM, Nelson K, Sun H, et al. The patient-centered medical home in the veterans health administration. Am $J$ Manag Care 2013; 19(7):e263-72.

15. Leung LB, Rose D, Stockdale S, et al. Regional adoption of primary caremental health integration in veterans health administration patientcentered medical homes. J Healthc Qual 2019;41(5):297-305. https:// doi.org/10.1097/JHQ.0000000000000206

16. Leung LB, Rubenstein LV, Yoon J, et al. Veterans health administration investments in primary care and mental health integration improved care access. Health Aff (Millwood) 2019;38(8): 1281-1288. https://doi.org/10. 1377/hlthaff.2019.00270

17. Goulet JL, Erdos J, Kancir S, et al. Measuring performance directly using the Veterans Health Administration electronic medical record: a comparison with external peer review. Med Care 2007;45(1):73.

18. Leung LB, Rubenstein LV, Post EP, et al. Association of veterans affairs primary care mental health integration with care access among men and women veterans. JAMA Netw Open. 2020;3(10):e2020955. https://doi. org/10.1001/jamanetworkopen.2020.20955

19. Leung LB, Post EP, Jaske E, Wells KB, Rubenstein LV. Quality of mental health care in integrated veterans affairs patient-centered medical homes: A national observational study. J Gen Intern Med 2019;34(12):2700-2701. https://doi.org/10.1007/s11606-019-05310-1

20. Nelson KM, Helfrich C, Sun H, et al. Implementation of the patientcentered medical home in the veterans health administration: Associations with patient satisfaction, quality of care, staff burnout, and hospital and emergency department use. JAMA Intern Med 2014;174(8):1350-1358.

21. Rosland AM, Wong E, Maciejewski M, et al. Patient-centered medical home implementation and improved chronic disease quality: a longitudinal observational study. Health Serv Res 2018;53(4):2503-2522. https:// doi.org/10.1111/1475-6773.12805

22. Gagne JJ, Glynn RJ, Avorn J, Levin R, Schneeweiss S. A combined comorbidity score predicted mortality in Elderly Patients Better Than Existing Scores. J Clin Epidemiol 2011;64(7):749-59. https://doi.org/10. 1016/j.jclinepi.2010.10.004

23. Benjamini $Y$, Hochberg $Y$. Controlling the false discovery rate: A practical and powerful approach to multiple testing. J R Stat Soc Ser B Methodol 1995;57(1):289-300

24. Solberg LI, Crain AL, Maciosek MV, et al. A stepped-wedge evaluation of an initiative to spread the collaborative care model for depression in primary care. Annals Family Med 2015;13(5):412-420.

25. Reiss-Brennan B, Brunisholz KD, Dredge C, et al. Association of Integrated team-based care with health care quality, utilization, and cost. JAMA. 2016;316(8):826-834. https://doi.org/10.1001/jama.2016.11232

26. Nelson K, Sylling PW, Taylor L, Rose D, Mori A, Fihn SD. Clinical quality and the patient-centered medical home. JAMA Intern Med 2017;177(7):10421044. https://doi.org/10.1001/jamainternmed.2017.0963

27. Miller BF, Brown Levey SM, Payne-Murphy JC, Kwan BM. Outlining the scope of behavioral health practice in integrated primary care: dispelling the myth of the one-trick mental health pony. Fam Syst Health. 2014;32(3):338.

28. Vickers KS, Ridgeway JL, Hathaway JC, Egginton JS, Kaderlik AB, Katzelnick DJ. Integration of mental health resources in a primary care setting leads to increased provider satisfaction and patient access. Gen Hosp Psychiatry 2013;35(5):461-467.

29. Chang ET, Rose DE, Yano EM, et al. Determinants of readiness for primary care-mental health integration (PC-MHI) in the VA health care system. J Gen Intern Med 2013;28(3):353-362. 
30. Gallo JJ. Multimorbidity and mental health. Am J Geriatr Psychiatry 2017;25(5):520-521. https://doi.org/10.1016/j.jagp.2017.02.007

31. Kessler RC, Ormel J, Demler O, Stang PE. Comorbid mental disorders account for the role impairment of commonly occurring chronic physical disorders: Results from the National Comorbidity Survey. J Occup Environ Med 2003;45(12):1257-1266.

32. Sanna L, Stuart AL, Pasco JA, et al. Physical comorbidities in men with mood and anxiety disorders: a population-based study. BMC Med 2013;11(1): 110 .

33. Browne $\mathrm{KC}$, Hoerster $\mathrm{KD}$, Piegari R, et al. Clinical care quality among Veterans Health Administration patients with mental illness following medical home implementation. Psychiatr Serv 2019;70(9):816-823.

34. Possemato K, Johnson EM, Beehler GP, et al. Patient outcomes associated with primary care behavioral health services: a systematic review. Gen Hosp Psychiatry 2018;53:1-11.
35. Dale H, Lee A. Behavioural health consultants in integrated primary care teams: A model for future care. BMC Fam Pract 2016;17(1):1-9.

36. Bravata DM, Myers LJ, Cheng E, et al. Development and validation of electronic quality measures to assess care for patients with transient ischemic attack and minor ischemic stroke. Circ: Cardiovasc Gual Outcomes 2017;10(9):e003157.

37. Yoon J, Chow A. Comparing chronic condition rates using ICD-9 and ICD-10 in VA patients FY2014-2016. BMC Health Serv Res 2017;17(1):572.

Publisher's Note: Springer Nature remains neutral with regard to jurisdictional claims in published maps and institutional affiliations. 